\title{
Out of Sight but Not Out of Mind
}

\author{
Harold Toliver \\ Department of English and Comparative Literature, University of California, Irvine, Irvine, CA, USA \\ Email: hetolive@uci.edu
}

How to cite this paper: Toliver, H. (2019). Out of Sight but Not Out of Mind. Advances in Literary Study, 7, 109-121. https://doi.org/10.4236/als.2019.73008

Received: December 30, 2018

Accepted: July 14, 2019

Published: July 17, 2019

Copyright $\odot 2019$ by author(s) and Scientific Research Publishing Inc. This work is licensed under the Creative Commons Attribution International License (CC BY 4.0).

http://creativecommons.org/licenses/by/4.0/

\begin{abstract}
Educational systems have a critical function in seeing to it that the curriculum covers the basics of the natural continuum, its time spans and spaces, temperature range, velocities, energy and matter exchanges. Beliefs ancient and modern incompatible with those basics became entrenched before much was known of the extremes of natural history from atoms to galaxies. Empiricism and observation in Copernicus, Tycho Brahe, Kepler, Galileo, Bacon, and the Royal Society started science and philosophy on the road to a much fuller account of it, but the extremes of the scalar spectrum continue to trouble both our understanding of the natural continuum and our means of representing it and teaching it.
\end{abstract}

\section{Keywords}

Empiricism, Discourse, Atoms, Natural Continuum, Standard Model, Groupthink, Scalar Spectrum

\section{Epigraph}

What unthinking people call design in nature is simply the reflection of our inevitable anthropomorphism. Whatever they can use, they think was designed for that purpose-the air to breathe, the water to drink, the soil to plant. It is as if they thought the notch in the mountains was made for the road to pass. (John Burroughs, "The Natural Providence", Accepting the Universe).

\section{The Natural Continuum}

The scalar spectrum from small to large and the extent of time and space put in perspective what we can perceive directly. Nearly everything from quarks to quasars falls outside the unassisted sensory range. We come by those limitations naturally. Our genetic ancestry didn't need to see X-rays or gamma rays. Muscles developed at a certain strength because of gravity. Ears responded to only certain 
sound waves. Besides what lies out of sight we have other reasons to keep the fuller range of reality in mind including knowing how to judge beliefs incompatible with it and with one another. They detract from the coordinated international effort that keeping the planet habitable requires. As recurrent conflict in the Middle East, exported terrorism, and persistent Muslim/Hindu turmoil in Pakistan and India demonstrate, the holy wars aren't over. Cultures remain tradition-bound not only in troubled regions but globally. They cling to beliefs derived mostly from the ancients, which in the West means primarily from the Greco-Roman and Judeo-Christian heritage. That shows in what Gallop polls find with respect to evolution with only about a fourth of Americans willing to turn it over to natural processes.

As John Burroughs (Burroughs, 1920) and numerous others have underscored, prevalent schools of thought have typically supplied anthropomorphic reasons for the way things are. If what is in question is a poisonous snake, the reason in a moral universe must be punitive. Someone must have done something seriously wrong or the weather wouldn't be so extreme. In Milton's version of that (Milton, 1957), taken mostly from scripture, the planet changes from paradise into its present condition as Adam and Eve are ushered out of the garden, sentenced to lives of hard labor ending in death. Like that storybook version of world history, other doctrines, beliefs, myths, romances, and epics-Hesiod's, Homer's, Virgil's, and Dante's, for instance-went where their cultures led. That wasn't where natural history tells us to go. To develop that point I want to put representative samples of the western tradition and its distrust of science alongside what has become a well established natural history.

What lies at the small end of the scale has always been as unknown as the macrocosm. Scientists and philosophers from the pre-Socratic philosopher Thales of Miletus (c.546) and Democritus ( $5^{\text {th }}$ century BCE) onward proposed on strictly logical, not observational, grounds that an atomic (non divisible) bottom level had to exist. Otherwise motion across space would be impossible for the reason Parmenides and Zeno gave. Any span of time or space would have to be halved, halved again, and again, toward but never reaching infinity. Atoms proposed partly in response to that quandary proved not to be a solution because atoms, too, even though by definition the word in Greek meant not divisible, have spans that thought can divide infinitely. Moreover, spaces between them are likewise divisible. The minimal units nuclear physics studies seemingly offer no help to philosophy confronted with the Zeno conundrum, not until, just possibly, recently in loop quantum gravity (LQG), spun out of Einstein's theory of gravity in general relativity. LQG has been proposed at any rate as something called a spinet work or spinfoam, its quanta on the order of a Planck length at $10^{-35} \mathrm{~m}$. Advanced by Carlo Rovelli and Lee Smolin among others, the LQG takes a step toward a theory of everything (TOE), using quanta with "loops" connecting one another to combine gravity, quantum mechanics, and spacetime. Such hooked-together quanta units are thought not to fill an already existing 
space but actually to constitute space, thus removing spans distances that have to be endlessly halved. As to infinitely dividing the quanta by thought, we don't really have to do that if they are truly minimal. What they are and not how we can imagine them is what counts.

What atoms actually are didn't come within the range of testing and of microscopes until the past century, nor did the grouping of stars in galaxies and the outward movement of the galaxies themselves. How far that century and this one have gotten is indicated by high powered electron microscopes that can peer into what were prematurely named atoms and show them to be composites. At the other end of the scalar spectrum modern telescopes in ultra deep field scans can see backward in time beyond the formation of first stars. Adjusting to what falls that far outside the customary sensory range is difficult for everyone, average or brilliant, fast or slow. Whereas revered traditions however farfetched attract the finest adjectives languages have and inspire magnificent art and architecture, atoms fill blackboards with equations and attract a nomenclature of quarks, gluons, fermions, and bosons. Getting inventive with what they call super partners, physicists add squarks, sleptons, gravitinos, and for good measure (pun unavoidable) zinos and winos. These are all out of unassisted sight range but come within reach of sensitive instruments of detection. They obviously aren't as inspirational as alternative universes with their monumental architecture and their equally invisible powers, these without any means of testing or proving but paying attention to people as galaxies billions of light years away do not.

\section{The Standard Model}

Our understanding of stretched scales is helped by nature's regularities and configurations, the products of constants and invariables. These guarantee that what is true one place is true everywhere. That gives our limited sensory range some leverage in making what falls within sight testify to what doesn't. In reverse, two galaxies seen merging far off and deep in the past tell astronomers something about what will happen in due course in the Milky Way's approach to Andromeda. Nothing violates nature's constants and invariables.

Anthropomorphic myths leverage the human range in an entirely different way, by creating powerful humanlike supernatural beings to work on nature. These are typically imagined to be approachable for tasks out of human reach as a rain dance prompts them to bring rain. Besides their being intangible and never seen, that has the disadvantage of assuming that the power that brought a hurricane will turn around and save those in its path. Any form of intelligent design has to account for nature's jumble, diseases, predation, and mortality as well as its beauty and its blessings. The best result of tested observation and theory in science so far in replacing myths with atomic matter evidence has been the standard model. Despite its lack of anyway to account for dark matter and dark energy it has a good enough pedigree to justify the word "standard", the following version one of many available on the internet (Figure 1). 


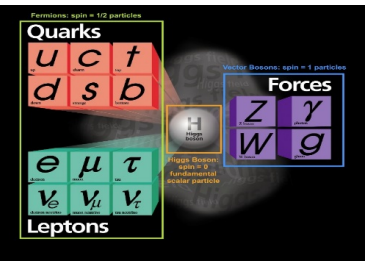

Figure 1. Standard model.

Comparing that to virtually any cultural heritage will show the incompatibility of their versions of what lies out of sight with the full range of the natural continuum. The standard model isn't yet a theory of everything since the nuclear strong force that binds protons and neutrons together can't yet be added to the electromagnetic-weak combination. Nor has the Weakly Interactive Massive Particle (WIMP) proposed for dark matter. Despite those and other gaps, we can treat the phrase natural continuum as a term of terms. Nothing known to exist falls outside its succession, which got underway some $13.799 \pm 0.021$ billion years ago as a particle plasma heated beyond calculation cooling enough by about the 380,000 year mark for electrons to join neutrons and protons in forming atoms. After years numbered in the hundreds of millions, dense clusters started forming into stars under gravity. For the projected end of the universe cosmologists provide only very tentative estimates, but spans of time overall range from the briefest Plank instants to when the Appalachian Mountains disappear, the sun turns into a red giant, and nucleons decay. The latter is to happen at about the $2 \times 10^{36}$ year mark if it doesn't take $10^{43}$ years. At the farthest extreme, a black hole with billions of solar masses, decaying by the Stephen Hawking evaporation process, is projected to end the black hole era at about $10^{106}$, the ultimate quiescence coming when no more energy or heat transfers from one thing to another and nothing any longer leaks out of black hole compaction.

Any projection that distant is speculative and borders on science fiction, but the astrophysics on which long range estimates are based is reasonably sound. Nature has explosions and collisions but not leaps or reversals. Natural history and natural continuum mean the same thing in that regard, and natural philosophy is charged not only with accounting for them but with their application to the history of ideas. Only after some 9 billion years did the sun and the satellite we ride around it collect their masses out of what cosmologists think was probably detritus thrown off from one or more supernovas.

\section{Whence Natural History?}

Reconciling natural history with any of the supernatural sources proposed for it has never come easy, but it started getting harder with the Renaissance resurgence of empiricism and observation. What Copernicus (1473-1543), Tycho Brahe (1646-1601), Galileo (1564-1642), and Johannes Kepler (1571-1630) were finding in the heavens didn't accord well with traditional beliefs. The micro- 
scopic phase got underway when Anton van Leewenhoek (1632-1723) put microbes under scrutiny and called them animalcules, squirming little things that also fascinated members of the Royal Society. Literary examples of science denial are similar to theological ones but more accessible and readable, so I'll stick with them for the time being. They wield common sense against the far-out and the small coming into view through magnification. The reservations over science and its undermining of beliefs continued from the $17^{\text {th }}$ through the $19^{\text {th }}$ century and have lingered in many places in the $20^{\text {th }}$ and $21^{\text {st }}$ as well.

So let us step back three centuries and listen first to objections from an exceptional mind and talent, Jonathan Swift, representative not only of the $18^{\text {th }}$ century but of the science denial. That still persists. School children, a few of them at least along with their elders, recited these lines from "Poetry: A Rhapsody" (1733):

Big fleas have little fleas,

Upon their backs to bite 'em,

And little fleas have lesser fleas,

And so, ad infinitum.

A variant, slightly more stately, gestures to philosophy and moves to a slower cadence, not quite as catchy for the preschool set but as satire more (mock) dignified:

So naturalists observe, a flea

Hath smaller fleas that on him prey,

And these have smaller fleas to bite 'em.

And so proceed ad infinitum.

Along with the tetrameter couplets, citing naturalists (scientists) is the main difference. Poets' getting bit from behind by smaller and smaller poets is the point, but meddling naturalists focusing on trivial subjects, Swift implies, also violate god-given human dignity. He made prying into nature objectionable on other occasions more specifically aimed at scientists as did his fellow satirist Alexander Pope as well. Since that remains typical except for being so well put, stay with the literature a moment longer. Swift hit full stride in mocking the "projectors" in Gulliver's Travels' academy of scientists at Lagado (Swift, 1960). Lacking faith in providence, a catchall super power that looks after people, the academy's astronomers obsess over close calls with disaster: "the earth, by continual approaches of the sun toward it, must in course of time be absorbed or swallowed. The earth narrowly escaped a brush from the tail of the last comet, which would have infallibly reduced it to ashes; and ... the next, which they have calculated for one and thirty years hence, will probably destroy us" (Voyage to Laputa, chapter 2 ). The mockery is as if such disasters weren't possible, which of course they have been throughout the history of the visible universe and the planet. In its earlier years the planet had an especially rough time of it sweeping out large chunks of debris in its path. Since then it has put its forms of life through several 
excruciating extinction episodes.

Disapproval of meddling into forbidden areas continued into the next centuries and as I suggested is still very much with us. It is the butt of satire in Mark Twain's scornful Tumble-Bug as well (Twain, 1996), disdainful of Manology (study of the extinct species Man). The species that have inherited the earth, including the snails and insects, agree with Tumble-Bug that "Science only needed a spoonful of supposition to build a mountain of demonstrated fact out of" The moral? Mankind should not be "prying into the August secrets of the Deity" (Sketches, 148). Since Twain's day the spoonfuls have multiplied into truckloads detailing the continuum. Secrets were the orthodox explanation for what couldn't be seen or understood. They existed in a divine mind rather than in scalar extremes and the far reaches of atomic matter.

Another tendency under that orthodox version of secrets was to make suffering out to be for the good of the sufferer. That is less prevalent today but still a factor in science denial. Confidence in Leibniz's best of all possible worlds gets Candide into one scrape after another. Its logic was that if in a well made, infallibly governed universe nothing can happen that isn't intended, it follows that what looks to be disastrous must not be. For mysterious reasons, victims of misfortune are intended to be just that. Where that didn't work as an explanation, rogue angels and human disobedience were traditionally called in as they were in Milton, whose story of the universe was the fullest version in English of everything from beginning to end. That nothing of the kind applies to a universe billions of years older than mankind and without visible angels no one knew for sure prior to the earlier $20^{\text {th }}$ century.

Prying into such forbidden areas had other repercussions not specifically for Swift but for $18^{\text {th }}$ century monarchies. That is an aside here, but a lingering sense of things forbidden does often lurk in the shadows of solemn piety. Those who distrusted providence or who got too inquisitive could end up questioning the civil and ecclesiastical hierarchies. These after all administer the laws and the sacraments that enable the devout to escape nature in the long run. The scale of normal observation had been set for good reason. As the starry heavens illustrated, far things weren't meant to be accessible. When Milton's Eve gets curious about them, that's more or less what she is told on no less an authority than her husband and the congenial archangel Raphael, sent to fill in events that came before Eden. The implicit admonition to keep to one's place calls for a submissive attitude that can carry over into social and political matters seemingly unrelated to philosophy and science. Keeping people ignorant, pious, and submissive contributed to science denial through the $18^{\text {th }}$ century and even the scoffing hasn't altogether disappeared when it comes to deriving Homo sapiens from apes.

\section{Archived Data}

Despite the skepticism over magnification and over science in general, $17^{\text {th }}$ and 
$18^{\text {th }}$ century naturalists continued labeling objects and filing away information about them. As Lorraine Daston and Peter Galison indicate in Objectivity (2010) (Daston \& Galison, 2010), $17^{\text {th }}$ century science compiled atlases, bestiaries, and botanical works containing unprecedented amounts of data. After the mid $17^{\text {th }}$ century, area publications included studies by members of the Royal Society, one of whom, Robert Hooke (1635-1703), had a microscope of his own. His first publication advertised on its cover page "physiological descriptions of minute bodies" and lived up to its claim with a blown up image of the eye of a fly and an example of a cell, a Hooke coinage (Hooke, 1665). A new world of marvels was opening up close at hand, this one devoid of miracles but in the minds of its observers not without design and intent. What Hooke saw he thought confirmed the divine plan. He was prepared to see it that way, and so he did, blocking off what contradicted his and nearly everyone's assumptions. Like it or not, a mosquito was meant to be just what it is. So were animalcules, not yet known to be guilty of inflicting diseases.

That Hooke's publication was popular didn't mean that it was known to the general public. Reading was still restricted to a fraction of the population if a somewhat larger fraction than a century and a half earlier when Thomas More (1478-1535) taught his daughters to read. Physics landed in its own university department during the lifetime of Newton (1642-1727), where mathematics already had a chair. Crucial to natural philosophy's future, Newton removed the traditional contrast of the celestial to the terrestrial sphere, one perfect and forever stable, the other constantly changing and subject to decay. In his demonstrations the same laws applied everywhere. Apples fall from trees, and planets orbit the sun. That removed one barrier to having natural laws prevail everywhere but also increased the gap between what observation was showing and what nearly everyone believed. It didn't of course speak to the distances, numbers of stars, or micro measurements.

The advances in $17^{\text {th }}$ century math, astronomy, physics, and microscopic science were followed by a century of unprecedented encyclopedic information gathering and a broadening reading public. Georges-Louis Leclerc, Comte de Buffon (1707-1788), collected data on flora and fauna into a 36 volume natural history (Histoire naturelle, générale et particulière, 1749-1788). What geology, astronomy, biology, chemistry, and physics were assembling remained only loosely connected. The notion of mutually supportive studies had to await better physics, geology, and biology. In popular understanding then and for the next two centuries what connected phases of natural history wasn't embedded in natural laws but was a master design hidden among divine mysteries. Needless to say there were lots of those in a nature given to tempests, droughts, and an occasional pestilence.

How far the interconnection of disciplines and questioning of orthodox beliefs had come by the mid $19^{\text {th }}$ century is clear in the mineralogist Alexander von Humboldt in the ambitious work Kosmos (Von Humboldt, 1858), the research for which took its author into jungles and up mountains. In putting the cosmic 
continuum in strictly naturalist terms, that was a milestone, published in more or less complete form in 1858. To Humboldt's way of thinking, what linked events and fields of study was a causal chain based entirely on natural laws. $\mathrm{He}$ accompanied ventures into the earth sciences with the promotion of that each-in-every and every-in-each principle. The continuum left nothing dangling. Whatever exists comes mechanically and by necessity. Though lacking a concept of evolution, Kosmos presupposed a greatly extended earth history that would support what came the following year in Darwin. What Humboldt had seen of Darwin's work up to 1858 was minor, but both required a drastically revised world history and an extension of time matching that of space outward downward into minimal particles and what became Plank instants. The core beliefs of the past were already in shreds with Humboldt and Darwin even if no one outside limited circles realized it and physicists hadn't yet found what an atom is.

Humboldt didn't spring out of nowhere. He had predecessors in earth sciences, especially James Hutton, a geologist and fellow student of mineralogy. In $A$ Theory of Earth (1785) Hutton found that because of vertical earth movement what was on the surface now hadn't always been (Hutton, 1788, 2010). Nothing in the brief calendar of a created universe accounted for that any more than theories of intelligent design do today. The movement was driven by heat, but the layers also accumulated by sedimentary means before melting and fusing into metamorphic rock. Clearly by The Origin of the Species (1859) the prevailing biblical view of world history in the Middle East and West was impossible to support logically. Either the powers behind the universe had chosen to work exclusively through nature and be manifest only there or no such powers existed.

If the disciplines were to collaborate in the pursuit of the natural continuum's succession, the data and theory from each area had to be on hand for the others. Data storage, retrieval, and distribution, coming in high volume in the $17^{\text {th }}$ and $18^{\text {th }}$ centuries, reached flood stages. Were Swift alive now he might want to add to his critique of microscopic trivia a companion satire, this one of heaped up facts-like this if he were having an off day:

So naturalists observe, a file

Hath smaller bits within its pile,

And these have mega mites

And so proceed to gigabytes.

And on to terabytes. The tera prefix $\left(10^{12}\right.$, trillion $)$ has been called into play often recently, as in the teragrams of $\mathrm{CO}_{2}$ and $\mathrm{CH}_{4}$ in the atmosphere, in the terabyte storage capacity of computers, and the centralized storage of One Drive and Cloud. That is no exaggeration. The particle theorist Sean Carroll tells us that at the Large Hadron Collider (LHC) at Cern particle collisions produce a billion megabytes of data at a rate of a billion collisions a second. What is to be recorded and presented obviously has to be selective. That ratio of discarding more than matches what the brain does in ignoring impressions streaming in. So numerous have the data become they require elaborate tiers of categories to put 
them in order, another organizing device to go with fast forwarding and offering approximate rather than exact numbers. Induction goes from incomposite (simple) bits and pieces to elaborate nomenclature pyramids under ever more inclusive titles. Mathematicians carry numbers only so far before resorting to the sign for infinity (00) or ad infinitum for the remainder. Technically no number can reach there, but as an absolute it makes a decisive reference point that means "and so on, and on, and on". In any case by the early $20^{\text {th }}$ century it was becoming clear to at least a few that the secrets were nature's and lay hidden in the scalar extremes of atoms and galaxies. Knowledge of these wasn't forbidden, but it was hard to come by.

\section{Language, the Self, and Philosophy}

The philosophical implications of a cosmos run exclusively by natural laws were evident in a good deal of post Darwin commentary. Attempts to reconcile other notions of origin nonetheless continued even among naturalists as far as post War I nature writing, somewhat surprisingly in essays by the American naturalist John Burroughs. Let us glance further back again for a moment, this time with philosophy rather than science as the subject. A century after Bacon, Pope (1734) argued in "An Essay on Man" (Pope, 1744), "Know then thyself, presume not God to scan":

The proper study of Mankind is man.

Plac'd on this isthmus of a middle state

A being darkly wise, and rudely great: ...

Sole judge of Truth, in endless Error hurl'd:

The glory, jest, and riddle of the World!

(Epistle II, 1-18)

The key lies in presume, the sin of Milton's Eve at the forbidden tree thinking she could rise in stature by a magical infusion of knowledge, not that bad an assumption given a talking serpent. Considerable knowledge had after all come from nowhere to both her and Adam, and so why not believe in magic?

As we've seen, the next two centuries saw a wealth of observation and theory from fossil studies to astronomy that tampered with the Aristotelian, Platonist, and theological heritage that philosophers from Hume and Descartes to Locke and Leibniz sought to combine with the new empiricism. Thanks partly to the Watson/Crick discovery of the DNA double helix (1953), the proper study of mankind has come to include things like the Hox gene that tells other genes what to do. By then it had become clear as Humboldt might have put it that the proper study of one thing is all the rest. The dark and rudely great, and the glory, jest, and riddle parts still held. The upshot now is that macrocosmic enormity and microcosmic diminution extend beyond anything the human brain can encompass except in abstractions and lumpsum numbers. These are based on a combination of observation and inference, as dark matter is inferred from its visible gravitational effects and a black hole by the activity around its event ho- 
rizon. Looking for intent in such things is futile.

Relations among the segments of nature's profusion can be found only by tracing each segment back to a mutual ancestry as in going from branches of the evolutionary tree to their supporting limbs and on down to the trunk. That is how complex forms of life in the millions came from the single cell (prokaryotic) kind that prevailed for three billion years. Still further back that is also the way prodigious natural production came from mottled near uniformity. Thanks to Arno Penzias and Robert Woodrow (1964) using radio wave astronomy to identify the Cosmic Microwave Background (CMB), information piled up from earlier had also become available. With that discovery came new problems not merely in inferring what couldn't be seen but in finding ways to make it intelligible. The difficulties of detecting what is out there bring difficulties in teaching in its train. They put additional strain on discourse, math, and visual such demonstrations as the standard model chart.

As to that branch of extended scales, a gap of sorts always exists between words and what they refer to. The continuum and extreme of measurements only aggravate them. Symbols work by putting something composed of letters in place of something real. The word is real in its own right, but it is halfway into the mind that uses it and interprets it, an in-between device, as a statue or painting is and isn't what it portrays. We are soused to that we don't stop to consider how variable the distance is between symbols and things. It is considerable in mathematical equations, less in ordinary words, and smaller still in onomatopoeia. It becomes quite large when the minimal Planck instant clocks in at $10^{-44} . E=m c^{2}$ as a form of expression bears no resemblance to energy and matter exchanges.

The postmodern branch of commentary on discourse and other forms of representation assumes that the barrier between things and ways to present them is insurmountable. Insofar as symbols and their referents are categorically different, that is true. That is what underlies the treachery of images in Rene Magritte's famous surrealistic painting of a pipe labeled "This is not a pipe". Without that label we might ignore the obvious fact that the two dimensional image on paper isn't an actual pipe. The recent commentary on discourse is formidable. We don't need an exhaustive list to demonstrate that, but a sample will give some indication of it. Notable contributions have come from Jude P. Dougherty (2013), Herbert W. Simons (1990), Michael Hogan (1998), Norman Fairclough (1992), Alan Gross and William Keith (1997), Luc Pauwels (2006), Leah Ceccarelli (2001), Daston and Galison (2010), Daston and Park (1998), W. H. Newton-Smith (1981), George Layoff and Mark Johnson (1980, 2003), Joseph Schwartz (1992), Hilary Putnam (1988, 1992), Peter Medawar (1984), Robin Dunbar (1995), John R. Searle (1998), and Alan Irwin (1996). Philosophers like Martin Heidegger, Paul Sartre, and Jacques Derrida worried their way earlier through similar discourse problems in a complex, tangled prose of their own. They weren't concerned with frames of reference that come with scalar spectrum extremes, but they were aware of the mind's taking shortcuts by means of sym- 
bols and equations. Just three words, the visible universe can sum up everything. Well, not quite actually, since as astrophysicists tell us $95 \%$ of the existing matter and energy of the universe is dark and has to be inferred rather than directly observed. It isn't visible but is definitely there.

Given cross checks and testing, trust in objectivity for most people isn't the problem Descartes raised concerning his infamous deceiving demon, but science denial by special interests exploits any miscalculation it can find, as the global-warming-is-a-hoax movement treats climatology as voodoo. In place of clever flea poems, its spokesmen turn to blogs, tweets, twitters, and sometimes bits and pieces of counter evidence. Evidence culling wasn't one of the traditional subjects of rhetoric, but argument relying on unrepresentative selections presupposes it. It is up to counter argument to cite what has been excluded, and in fields as complex as climate change it isn't always clear what should and shouldn't be left out. Long term trends, measurements region by region over extended spans, and atmospheric chemistry compete for attention with recent trends. Hanging over any data collection is the potential charge that it is trivial, that it amounts only to fleas on the back of fleas.

Another way to avoid natural history is to say that what observation reveals has no bearing on spiritual matters. That raises a different aspect of the word-referent relation and echoes Milton's and Pope's warning against prying into forbidden secrets. The result is a bi-level discourse that applies different standards to the two levels. Descartes is one of the most cited examples, but Hume, Hobbes, Locke, and several others entertained versions of vastly different material and spirit worlds. That the many versions of spiritual realms differ by era and region and disagree on basics indicates that they are the product of groupthink, all the more so when they add nationalism to the articles of belief. Keeping a presiding force like the Holy Spirit safeguarded from empiricism and at the same time having everything that exists derive from it has led into bottomless philosophic quagmires. It is another way to make what is invisible a divine mystery rather than parts of nature that extend beyond the sensory range. It also divides people into body and soul, leaving out mind, memory, and accumulated experience. A better way might be to assign individual points of view not to a vaporous soul or spirit but to the invariable self consisting of a place-from-which one sees and thinks. Individualizing the self doesn't change that from-which location any more than changing the numbers for $x, y$, and $z$ changes the equation $x+y=z$. The format remains the same whatever goes into it.

Falling back on a universal super spirit raises other questions as well. Long before the rise of $17^{\text {th }}$ century empiricism, disorder and irregularity looked like anomalies in what was presumed to be infallibly created and governed. In Jewish, Christian, and Muslim doctrine, irregularity and disorder stemmed from angel and human transgressions. The trouble with that always was that it didn't account for the same fate afflicting the good and bad alike, for the suffering and mortality of non moral creatures, and for irregularities beyond the reach of hu- 
mans and angels. When evolution extended nature much longer than humankind had existed, sweeping science denial became the only option left, not exactly the customary mistake Humboldt singles out in a witty threesome but similar to it: "First people deny it is true; then they deny it is important; finally they credit the wrong person".

Confusion and imperfection in nature's proliferation have never been hard to explain in the naturalist terms that Hutton and Humboldt used and empiricism prefers. The stronger cohesive forces have too little range, and electromagnetic and gravitational forces that do have range can't prevent eruptions, agitation from heat, collisions, and other kinds of perturbation. Moreover, under thermodynamics the bonding forces are also breaking forces. Heat as transferred energy breaks lighter isotopes apart to create heavier ones. Gravity and transmitted electromagnetic energy bring collisions. Gravity holds earth to its orbit around the sun and at the same time pulls asteroids into contact with it. By exercising an equal tug in all directions it shapes molten masses into spheres, but as belts of debris illustrate that doesn't collect all the debris dispersed from a celestial disintegration. Nor does it prevent turbulence in the interior and on the surfaces of stars and planets. On the one satellite we know well, uneven cooling empowers plate tectonics, earthquakes, and the rising of plumes that at the surface convert magma into lava and leave broken fields of rock. They also sometimes blow the tops off mountains.

Under universal natural laws, matter/energy interactions bring wrinkles and cracks in terrain on other planets as well as earth. The recently observed collision of two neutron stars, the leftover cores of disintegrated supernovas, added to the known kinds of celestial disturbance. That was another case of an Einstein prediction based on constants, this one shooting off gamma rays and gravitational wave "chirps". Underfoot and in evidence in many places are just such examples of competing forces at work, open on the planet to air movement that can parch a desert, flood a lowland, and hurl a typhoon at an island. That has never been a secret, merely something to be explained away.

Another branch of what lies out of sight but not out of mind is the one proposed by Kant. His redefining the spirit realm as something called a mental noumenon offers a compromise of sorts between spiritual and material explanations. Concepts of a priori space and time become "mere creations of the imagination" that have their source "in experience, inasmuch as, out of relations abstracted from experience, imagination has made up... general statements of these relations". No application "can be made without the restrictions attached thereto by nature" (from The Critique of Pure Reason) (Kant, 1787). A hypothetical designer might or might not exist but to Kant, who like everyone of his day lacked the necessary cosmology and physics, it remained a useful idea. In moving from philosophy part way into psychology, Kant suggests the real reason for anthropomorphism. It is a thought invention bolstered by groupthink and keeps its distance from tangible evidence. 
Naturalists and scientists like Hutton and Humboldt set a good many such metaphysical, ontological, and epistemological problems aside simply by eliminating what can't be seen or logically inferred. They too of course couldn't formulate a comprehensive theory of natural history since no one could see small enough and far enough to identify what was needed to do so, they nonetheless provided a framework for understanding the continuum. Bringing what was far off and what was small into visibility required improved instruments of detection.

\section{Conclusion}

When we apply what is reasonably well established in natural history to common beliefs around the globe we find them vague, contradictory, and unreliable. They don't explain nature's vast extent, its age, its rough-hewn harshness, its disorderly areas, or its range of temperature from millions of degrees to zero. Because so much of natural history falls outside our sensory range we tend to ignore what it says about what does fall within our range. Beliefs otherwise postulated impede international efforts to keep the planet habitable. Educational systems needn't point that out about them, but they should at least make their students aware of how atomic matter works, how much of it is invisible, how far it extends, how old it is, where it seems to be headed, and especially what a narrow range of measurements lifeforms can tolerate under the unforgiving laws of physics, chemistry, biology, and botany. Its recurrent advice is to take care. The planet contains practically all that falls within our reach.

\section{Conflicts of Interest}

The author declares no conflicts of interest regarding the publication of this paper.

\section{References}

Burroughs, J. (1920). Accepting the Universe: Essays in Naturalism. Boston: Houghton Mifflin.

Daston, L., \& Galison, P. (2010). Objectivity. New York: Zone Books.

Hooke, R. (1665). Micrographia: Or Some Physiological Descriptions of Minute Bodies Made by Magnifying Glasses with Observations and Inquiries Thereupon. London: Jo. Martyn and J. Allestry. https://doi.org/10.5962/bhl.title.904

Hutton, J. (1788, 2010). A Theory of the Earth. New York: Classic Books International.

Kant, I. (1787). The Critique of Pure Reason (Trans. Meiklejohn, J.M.D., Kindle ed.).

Milton, J. (1957). Complete Poems and Major Prose. New York: Macmillan.

Pope, A. (1744). (Kindle ed.).

Swift, J. (1960). Gulliver's Travels and Other Writings. Boston: Houghton Mifflin.

Twain, M. (1996). Sketches New and Old. New York: Oxford University Press.

Von Humboldt, A. (1858). Works (Trans. Otté, E.C., Kindle ed.). 